\title{
COMUNICAÇÃO
}

\section{POTENCIAL DE RECUPERAÇÃO FÍSICA DE UM \\ LATOSSOLO VERMELHO, SOB PÁSTAGEM DEGRADADA, INFLUENCIADO PELA APLICAÇÃO DE CAMA DE FRANGO ${ }^{1}$}

\author{
Potencial of physical recovery of a red latosol, under degraded pasture, \\ as affected by the apllication of chicken manure
}

\author{
Adriana Monteiro da Costa², Elias Nascentes Borges ${ }^{3}$, Adriane de Andrade Silva 4 , \\ Antônio Nolla ${ }^{5}$ Ednaldo Carvalho Guimarães ${ }^{6}$
}

\begin{abstract}
RESUMO
A criação intensiva de frango gera uma grande quantidade de resíduos ricos em nutrientes cujo uso agrícola pode ser viabilizado pelos produtores, na adubação das culturas comerciais. Objetivou-se avaliar a influência da fertilização com cama de frango na recuperação física de um Latossolo. O experimento foi instalado em um Latossolo Vermelho Distrófico típico, textura média, sob pastagem degradada de Brachiaria decumbens Stapf. Os tratamentos estudados foram: 0, 1.200, 2.400, $4.800 \mathrm{~kg} \mathrm{ha}^{-1} \mathrm{de}_{\text {cama-frango }}$ e $2.400 \mathrm{~kg} \mathrm{ha}^{-1}$ de cama-frango + adubação mineral com $36 \mathrm{~kg} \mathrm{ha}^{-1} \mathrm{~N}, 60 \mathrm{~kg} \mathrm{ha}^{-1} \mathrm{~K}_{2} \mathrm{O}$ e $60 \mathrm{~kg} \mathrm{ha}^{-1} \mathrm{de}_{2} \mathrm{O}_{5}$. As aplicações foram realizadas em janeiro de 2004 e o solo amostrado em duas épocas distintas (60 e 210 dias após aplicação), nas profundidades de 0-20 e 20-40 $\mathrm{cm}$, para a caracterização dos atributos físicos: argila dispersa em água, grau de floculação, densidade do solo e porosidade total. O teor de argila dispersa em água decresceu com o aumento das doses de cama aplicadas e, conseqüentemente, houve um incremento no grau de floculação; houve uma pequena redução na densidade do solo e na porosidade total. Os atributos físicos do solo avaliados responderam com maior intensidade às aplicações de cama de frango nas doses variando de 2.666 a $3.750 \mathrm{~kg} \mathrm{ha}^{-1}$.
\end{abstract}

Termos para indexação: Atributos físicos do solo, adubação orgânica, cama de aves.

\section{ABSTRACT}

Poultry facilities generate great amount of residues rich in nutrients, which may be used by farmers to fertilize their crops. The aim of this work was to evaluate the effect of the fertilization with chicken manure on the physical recovery of the structure of a Latosol. The experiment was carried out in a loamy typic dystrophic Red Latosol, at Brachiaria decumbens Stapf. degraded pastureland. The treatments were: $0 ; 1,200 ; 2,400 ; 4,800 \mathrm{~kg} \mathrm{ha}^{-1}$ of chicken manure; and 2,400 kg ha-1 of chicken manure + chemical fertilizer with $36 \mathrm{~kg} \mathrm{ha}^{-1} \mathrm{~N} ; 60 \mathrm{~kg} \mathrm{ha}^{-1}$ of $\mathrm{K}_{2} \mathrm{O}$; and $60 \mathrm{~kg} \mathrm{ha}^{-1}$ of $\mathrm{P}_{2} \mathrm{O}_{5}$. The treatments were applied in January 2004. Sixty and 210 days after, the soil was sampled at the 0-20 and $20-40 \mathrm{~cm}$ depths. The physical attributes measured were: water dispersible clay, flocculation index, bulk density and total porosity. The water dispersible clay decreased with the increase of the dosage of manure applied; there was an increase in the flocculation index as the manure doses increased. There was a small reduction in soil bulk density and total porosity with the application of manure. The soil physical attributes evaluated were greatly affected by applications of chicken manure in the dose range of 2,666 to $3,750 \mathrm{~kg} \mathrm{ha}^{-1}$.

Index terms: Soil physical attributes, organic fertilization, poultry manure.

\section{(Recebido em 26 de abril de 2006 e aprovado em 19 de março de 2008)}

A região do Cerrado destaca-se no cenário agropecuário brasileiro como importante pólo produtor de soja, milho, suínos e aves. A demanda mundial por alimentos de qualidade e de baixo custo, aliado a problemas sanitários de mercados externos, como a "gripe do frango", impulsionaram as exportações brasileiras de frango e

\footnotetext{
${ }^{1}$ Parte da Dissertação de Mestrado da primeira autora apresentada ao Departamento de Pós-graduação em Agronomia da Universidade Federal de Uberlândia - UFU

2Geógrafa, Doutora em Ciência do Solo - Rua Tapajós, 1052 - São Francisco - 35700-511 - Sete Lagoas, MG - drimonteiroc@yahoo.com.br

${ }^{3}$ Engenheiro Agrônomo, Doutor em Solos e Nutrição de Plantas, Professor Adjunto - Instituto de Ciências Agrárias/ICIAG - Universidade Federal de Uberlândia/UFU - Avenida Pará, 1720, Bloco 2E, Sala 5 - Campus Umuarama - Umuarama - Cx. P. 593 - 38400-902 - Uberlândia, MG - elias@ufu.br ${ }^{4}$ Zootecnista, Doutoranda em Zootecnia - Faculdade de Ciências Agrárias e Veterinárias/FCAV - Universidade Estadual Paulista/UNESP - Via de Acesso Professor Paulo Donato Castellane, s/n - 14884-900 - Jaboticabal, SP - zoodrika@uol.com.br - Bolsista da CAPES ${ }^{5}$ Engenheiro Agrônomo, Doutor em Ciência do Solo, Professor Adjunto - Departamento de Agronomia/DAG - Universidade Estadual de Maringá/UEM Estrada da Paca, sn - São Cristóvão - 87500-000 - Umuarama, PR - nolla23@hotmail.com

${ }^{6}$ Engenheiro Agrícola, Doutor em Engenharia Agrícola, Professor Adjunto - Faculdade de Matemática/FAMAT - Universidade Federal de Uberlândia/UFU Avenida João Naves de Ávila, 2160 - Campus Santa Mônica - 38400-902 - Uberlândia, MG - ecg@ufu.br
} 
projetaram o Brasil no cenário internacional, tornando-o o segundo maior produtor mundial e primeiro exportador de carne de frango (EDWARD, 2004).

Os resíduos provenientes da criação intensiva de frangos, denominados de cama de frango, são ricos em nutrientes e, por estarem disponíveis nas propriedades a um baixo custo, podem ser viabilizados pelos produtores na adubação das culturas comerciais. A dose de cama a ser recomendada deve levar em consideração as necessidades da cultura e propriedades físicas e químicas do solo. Muitos trabalhos, principalmente no sul do Brasil, têm demonstrado a viabilidade da utilização da cama de frango como fertilizante (ANDREOLA, 1996; ERNANI, 1981; GIANELLO \& ERNANI, 1983; HOLANDA et al., 1982; MELLO \& VITTI, 2002; MENEZES et al., 2004). No entanto, há carência de trabalhos que estudem os efeitos dessa fertilização nos atributos físicos do solo, principalmente na região dos Cerrados. Os efeitos benéficos dos resíduos de animais nas propriedades físicas do solo dependem de características intrínsecas do solo. Solos com boas qualidades físicas, assim como elevados teores de nutrientes, tendem a não responder de forma significativa à aplicação desses resíduos. Espera-se que os efeitos sejam mais evidentes em solos naturalmente pobres e com algum grau de degradação.

Objetivou-se, neste trabalho, avaliar a influência da aplicação de cama de frango na recuperação física de um Latossolo Vermelho sob pastagem degradada na região do Cerrado, em Uberlândia, MG.

O experimento foi realizado em um Latossolo Vermelho Distrófico típico (LVd) (EMBRAPA, 2006), textura média, sob pastagem degradada de Brachiaria decumbens Stapf. implantada há 10 anos, a uma altitude média de 800 $\mathrm{m}$, declive de $2 \%$, localizado no município de Uberlândia, MG. O clima da região é do tipo Aw (Classificação de Köppen), apresentando no período estudado, janeiro a agosto de 2004, uma precipitação média mensal de 1.074 $\mathrm{mm}$, distribuída irregularmente e concentrada nos meses de janeiro, fevereiro, março e início de abril.
Foram coletadas amostras deformadas nas camadas de 0-20 e 20-40 cm para caracterização química (EMBRAPA, 1997) e física (Tabela 1) do solo estudado. A caracterização física envolveu a realização da análise textural com o uso de dispersante químico $\mathrm{NaOH} 1 \mathrm{~mol} \mathrm{~L}^{-1}$ pelo método da pipeta (DAY, 1965; EMBRAPA, 1997) e densidade de partículas, pelo método do balão volumétrico (BLAKE \& HARTGE, 1986; EMBRAPA, 1997).

A cama de frango foi proveniente de criação intensiva de frangos de corte coletada após a saída do terceiro lote de frangos, cujo período de criação é de aproximadamente 35 dias por ciclo, criados em galpão sob substrato de casca de arroz. Após a obtenção, o resíduo foi estabilizado por um período de 30 dias, sendo, então, realizada a caracterização química e física (Tabela 2), de acordo com metodologia proposta por Sarrude \& Haag (1974), com posterior aplicação dos materiais orgânicos curtidos.

As doses de cama de frango aplicadas no solo foram determinadas com base no teor de fósforo do resíduo, por ser esse um dos nutrientes mais limitantes ao desenvolvimento das gramíneas, principalmente em solos degradados. Os cálculos foram feitos conforme Menezes et al. (2004), em que o valor de P, obtido pela análise química, foi multiplicado por 2,29, obtendo-se o teor em $\mathrm{P}_{2} \mathrm{O}_{5}$ na cama e buscando agregar ao solo, na dose máxima, o equivalente a $120 \mathrm{~kg} \mathrm{ha}^{-1}$ de $\mathrm{P}_{2} \mathrm{O}_{5}$. Os tratamentos consistiram da aplicação de $0,1.200,2.400$, $4.800 \mathrm{~kg} \mathrm{ha}^{-1}$ de cama de frango e $2.400 \mathrm{~kg} \mathrm{ha}^{-1}$ de cama de frango + adubação mineral com $36 \mathrm{~kg} \mathrm{ha}^{-1} \mathrm{~N}, 60 \mathrm{~kg} \mathrm{ha}^{-1}$ $\mathrm{K}_{2} \mathrm{O}$ e $60 \mathrm{~kg} \mathrm{ha}^{-1}$ de $\mathrm{P}_{2} \mathrm{O}_{5}$. A aplicação foi realizada a lanço, em cobertura, sem incorporação (janeiro de 2004). A adubação mineral foi realizada manualmente e a aplicação da cama de frango foi realizada mecanicamente utilizandose uma distribuidora de resíduos sólidos. Após a aplicação, a pastagem passou por um período de diferimento, ou seja, durante 120 dias não houve pastejo animal na área. Esse período foi necessário para que a cama, aplicada superficialmente, fosse mineralizada, e para

Tabela 1 - Caracterização química e física do Latossolo Vermelho Distrófico típico (LVd) do município de Uberlândia, MG.

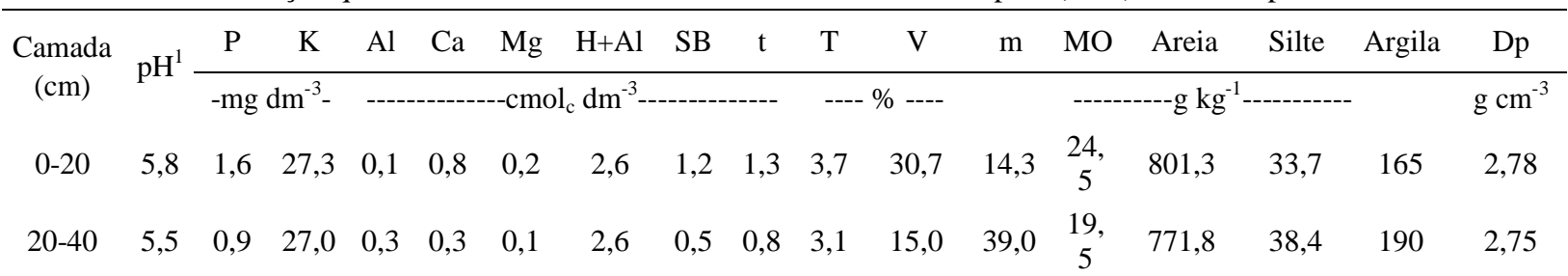

${ }^{1} \mathrm{pH}$ em H $\mathrm{H}_{2} \mathrm{O}$ (relação 1:2,5); P, K: extrator ( $\mathrm{HCl} 0,05 \mathrm{~mol} \mathrm{~L}^{-1}+\mathrm{H}_{2} \mathrm{SO}_{4}$ 0,025 mol L-1); $\mathrm{Al}, \mathrm{Ca}, \mathrm{Mg}$ : extrator (KCl 1 mol L-1); SB: soma de bases; t: CTC efetiva; T: CTC a pH 7,0; V: saturação por bases; m: saturação por alumínio. MO: matéria orgânica; Dp: densidade de partículas. 
Tabela 2 - Caracterização química e física da cama de frango, utilizada no experimento em Uberlândia, MG, novembro de 2003.

\begin{tabular}{lcc}
\hline \multicolumn{1}{c}{ Característica } & $\begin{array}{c}\text { Umidade } \\
\text { Natural }\end{array}$ & $\begin{array}{c}\text { Base seca } \\
\left(110^{\circ} \mathrm{C}\right)\end{array}$ \\
\hline $\mathrm{pH}$ em $\mathrm{CaCl}_{2} 0,01 \mathrm{~mol} \mathrm{~L}^{-1}$ & 8,2 & - \\
Umidade total $\left(\mathrm{g} \mathrm{kg}^{-1}\right)$ & 38,2 & - \\
Matéria orgânica total $\left(\mathrm{g} \mathrm{kg}^{-1}\right)$ & 455,5 & 737,0 \\
Carbono total $\left(\mathrm{g} \mathrm{kg}^{-1}\right)$ & 253,0 & 409,4 \\
Carbono orgânico $\left(\mathrm{g} \mathrm{kg}^{-1}\right)$ & 157,1 & 254,2 \\
Resíduo mineral total $\left(\mathrm{g} \mathrm{kg}^{-1}\right)$ & 162,5 & 263,0 \\
Resíduo mineral solúvel $\left(\mathrm{g} \mathrm{kg}^{-1}\right)$ & 79,7 & 129,0 \\
Resíduo mineral insolúvel $\left(\mathrm{g} \mathrm{kg}^{-1}\right)$ & 82,8 & 134,0 \\
Fibra Bruta $\left(\mathrm{g} \mathrm{kg}^{-1}\right)$ & 16,5 & - \\
$\mathrm{N}$ total $\left(\mathrm{g} \mathrm{kg}^{-1}\right)$ & 13,3 & 21,6 \\
P total $\left(\mathrm{g} \mathrm{kg}^{-1}\right)$ & 6,8 & 10,9 \\
K total $\left(\mathrm{g} \mathrm{kg}^{-1}\right)$ & 15,1 & 24,5 \\
Ca total $\left(\mathrm{g} \mathrm{kg}^{-1}\right)$ & 11,2 & 18,1 \\
Mg total $\left(\mathrm{g} \mathrm{kg}^{-1}\right)$ & 2,7 & 4,4 \\
$\mathrm{~S}$ total $\left(\mathrm{g} \mathrm{kg}^{-1}\right)$ & 2,5 & 4,1 \\
Cu total $\left(\mathrm{mg} \mathrm{kg}^{-1}\right)$ & 242,9 & 393,0 \\
Mn total $\left(\mathrm{mg} \mathrm{kg}^{-1}\right)$ & 200,9 & 325,0 \\
Zn total $\left(\mathrm{mg} \mathrm{kg}^{-1}\right)$ & 86,5 & 140,0 \\
Fe total $\left(\mathrm{mg} \mathrm{kg}^{-1}\right)$ & 646,4 & $1.046,0$ \\
B total $\left(\mathrm{mg} \mathrm{kg}^{-1}\right)$ & 7,3 & 11,8 \\
Na total $\left(\mathrm{mg} \mathrm{kg}^{-1}\right)$ & & $2.800,0$ \\
Relação C/N $(\mathrm{C}$ total$/ \mathrm{N} \mathrm{total})$ & $19 / 1$ \\
\hline
\end{tabular}

evitar a presença de resíduos sobre a forragem, quando do retorno do pastejo animal, que ocorreu no início de maio de 2004, com uma lotação de 0,9 unidade animal por hectare.

Após 60 dias (Época 1) e 210 dias (Época 2) da aplicação dos tratamentos, foram retiradas 4 amostras deformadas, aleatoriamente, em cada parcela experimental, as quais formaram uma única amostra composta (1 repetição), nas camadas de solo 0-20 e $20-40 \mathrm{~cm}$. Para determinação da argila dispersa em água (ADA), empregouse o método da pipeta, sem uso de dispersante químico, conforme Embrapa (1997). O grau de floculação foi calculado pela equação:

$$
G F=\frac{(A T-A D A)}{A T} \times 100
$$

Em que, $G F$ é o grau de floculação, em \%; AT é a argila total, em $\mathrm{g} \mathrm{kg}^{-1}$, e ADA é a argila dispersa em água, em $\mathrm{g} \mathrm{kg}^{-1}$.

Foram coletadas também amostras indeformadas em anéis volumétricos com capacidade de $80 \mathrm{~cm}^{3}$, com auxílio do amostrador tipo Uhland. A densidade do solo foi calculada pela relação entre a massa de solo seco em estufa a $105^{\circ} \mathrm{C}$, por 48 horas com o volume do anel, expressando-se o resultado $\mathrm{em}_{\mathrm{g} \mathrm{cm}} \mathrm{cm}^{-3}$. A porosidade total (Pt) foi calculada segundo Embrapa (1997), segundo a equação:

$$
P t=\left(1-\frac{D s}{D p}\right)
$$

Em que, Pt é a porosidade total, em $\mathrm{m} \mathrm{m}^{-3}$; Ds é a densidade do solo, em $\mathrm{g} \mathrm{cm}^{-3}$ e Dp é a densidade de partículas, em $\mathrm{g}$ $\mathrm{cm}^{-3}$.

O delineamento experimental utilizado foi o de blocos casualizados (DBC), com quatro repetições, em esquema fatorial $4 \times 2$, sendo 4 doses de cama de frango e 2 profundidades +2 tratamentos adicionais (adicional $1=$ $2.400 \mathrm{~kg} \mathrm{ha}^{-1}$ de cama de frango + adubação mineral, na profundidade de $0-20 \mathrm{~cm}$ e adicional $2=2.400 \mathrm{~kg} \mathrm{ha}^{-1} \mathrm{de}$ cama de frango + adubação mineral, na profundidade de 20-40 cm), totalizando 40 unidades experimentais. Cada parcela experimental teve área total de $250 \mathrm{~m}^{2}(25 \times 10 \mathrm{~m}) \mathrm{e}$ área útil de $150 \mathrm{~m}^{2}$ (15 x $\left.10 \mathrm{~m}\right)$. Utilizou-se para análise dos dados o software Sisvar (FERREIRA, 2000).

Durante as duas épocas de amostragens, foram observadas, em campo, alterações de importância para a discussão dos resultados obtidos. Aos 60 dias após aplicação dos tratamentos (Época 1), as raízes da braquiária concentravam-se na camada de $0-20 \mathrm{~cm}$, sendo quase inexistentes na camada subsuperficial. Aos 210 dias (Época 2), o sistema radicular encontrava-se melhor distribuído no perfil do solo, com grande presença desse também na camada de $20-40 \mathrm{~cm}$. A grande concentração de raízes na Época 2, assim como a menor umidade do solo, dificultaram a coleta de amostras para a análise de densidade do solo.

Os valores médios de argila dispersa em água (ADA), obtidos para as Épocas 1 e 2 (60 e 210 dias após aplicação dos tratamentos), são apresentados, respectivamente, nas Figuras 1a e 1b. Observa-se efeito significativo entre as doses de cama de frango e profundidades de amostragem, para as Épocas $1(\mathrm{P}=0,0092)$ e $2(\mathrm{P}<0,0001)$. 


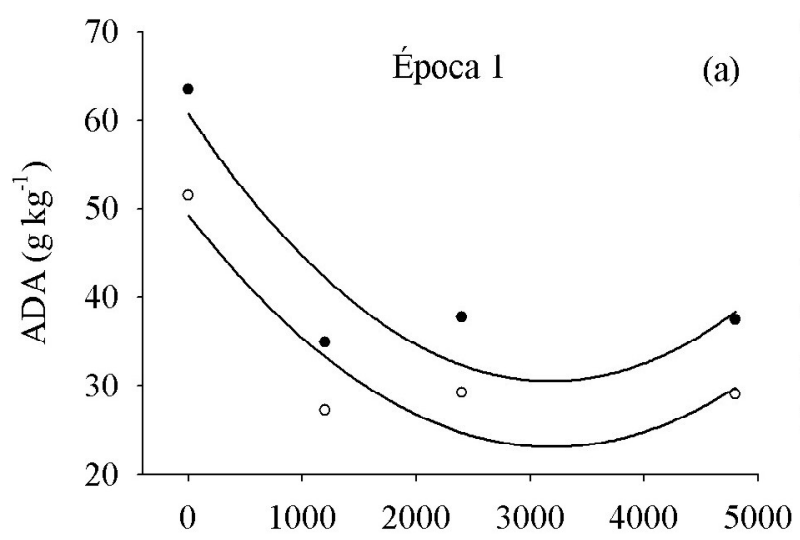

Dose de cama de frango $\left(\mathrm{kg} \mathrm{ha}^{-1}\right)$

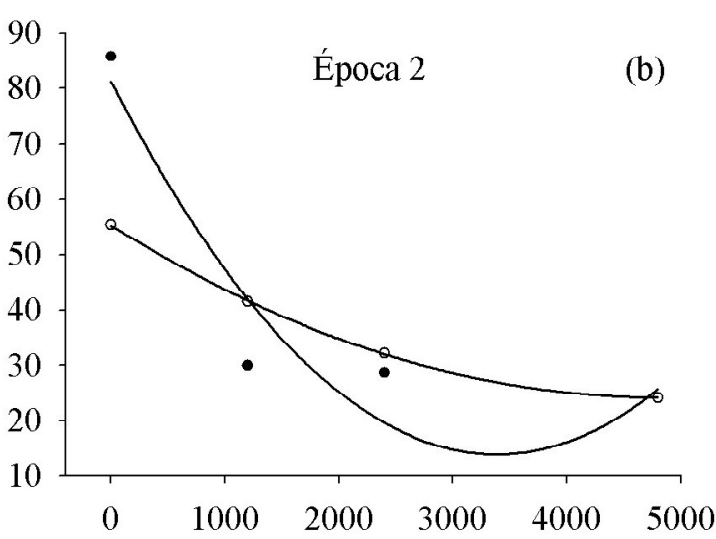

Dose de cama de frango $\left(\mathrm{kg} \mathrm{ha}^{-1}\right)$

- $0-20 \mathrm{~cm} \quad \mathrm{y}=0,000003 \mathrm{x}^{2}-0,019 \mathrm{x}+60,72$ $\left(\mathrm{R}^{2}=0,83\right)$

- $\quad 0-20 \mathrm{~cm} \quad \mathrm{y}=0,000006 \mathrm{x}^{2}-0,04 \mathrm{x}+81,23$

$\left(\mathrm{R}^{2}=0,90\right)$

- $\quad 20-40 \mathrm{~cm} \quad \mathrm{y}=0,000003 \mathrm{x}^{2}-0,016 \mathrm{x}+49,28$ $\left(\mathrm{R}^{2}=0,84\right)$

$$
\begin{aligned}
& 20-40 \mathrm{~cm} \quad y=0,000001 x^{2}-0,013 x+55,27 \\
& \left(R^{2}=0,99\right)
\end{aligned}
$$

Figura 1 - Valores médios para os teores de argila dispersa em água (ADA), para o Latossolo Vermelho Distrófico típico (LVd), em função dos tratamentos com cama de frango, nas profundidades de 0-20 e 20-40 cm, nas Épocas 1 (a) e 2 (b).

Para as duas épocas, observou-se uma redução nos teores de ADA com o aumento das doses de cama de frango aplicadas. Na Época 1, a redução nos valores ocorreu até atingir um valor mínimo de ADA de $30,67 \mathrm{~g} \mathrm{~kg}^{-1}$, na dose de $3.166 \mathrm{~kg} \mathrm{ha}^{-1}$ de cama de frango. Na profundidade de 20-40 $\mathrm{cm}$, o valor mínimo $\left(27,95 \mathrm{~g} \mathrm{~kg}^{-1}\right)$ foi observado na dose de $2.666 \mathrm{~kg} \mathrm{ha}^{-1}$ de cama de frango. A partir desses valores, há uma tendência de incremento nos teores de ADA, com o aumento da dose de cama de frango. Comparando as profundidades, observa-se que os maiores teores de ADA foram obtidos para a profundidade de $0-20 \mathrm{~cm}$, o que pode estar relacionado ao efeito deletério da pressão exercida pelo pisoteio animal, durante 10 anos, sem um manejo adequado da cobertura vegetal do solo. Efeito do pisoteio animal na estrutura do solo também foi observado por Bertol et al. (2000).

Analisando os dados obtidos na época 2, observase que o menor valor de $\operatorname{ADA}\left(14,57 \mathrm{~g} \mathrm{~kg}^{-1}\right)$ foi obtido com a dose de $3.333 \mathrm{~kg} \mathrm{ha}^{-1}$ de cama de frango, na profundidade de 0-20 cm. Os teores de ADA são inferiores para a camada superficial do solo $(0-20 \mathrm{~cm})$, até a aplicação da dose de $4.800 \mathrm{~kg} \mathrm{ha}^{-1}$ de cama de frango; acima dessa dose, há uma tendência a menores valores de ADA para a profundidade de 20-40 cm. Comparando-se os dados das épocas de amostragem, os menores valores de ADA foram obtidos para a Época 2, o que deve estar relacionado ao desenvolvimento da braquiária no decorrer do período. O crescimento de raízes pode ter promovido a aproximação das partículas do solo por força mecânica (CAMPOS et al., 1999; KIEHL, 1979; SILVA \& MIELNICZUK, 1997), liberação de agentes cimentantes e também fornecimento de nutrientes para os microrganismos que, por sua vez, contribuíram para a aproximação das partículas do solo, pela liberação de exsudados (PALADINI \& MIELNICZUK, 1991), como polissacarídeos, aumentando o grau de floculação das argilas e reduzindo os teores de argila dispersa. Esses resultados diferem dos obtidos por Andreola et al. (2000) em experimento com aplicação de $5.312 \mathrm{~kg} \mathrm{ha}^{-1}$ de esterco de aves, para uma Terra Roxa Estruturada já que esses autores não observaram efeito significativo dos teores de ADA, após 3 anos de experimento. Os efeitos benéficos da adubação orgânica, nos atributos físicos do solo parecem manifestar-se mais rapidamente em solos com maior grau de degradação.

Observou-se um efeito significativo das doses de cama de frango e profundidades de amostragem, no grau de floculação das argilas (GF), para ambas as épocas de amostragem $(\mathrm{P}<0,0001)$. Os valores médios do GF para as épocas 1 e 2, são apresentados, respectivamente, na Figura $2 \mathrm{a}$ e $2 b$. 


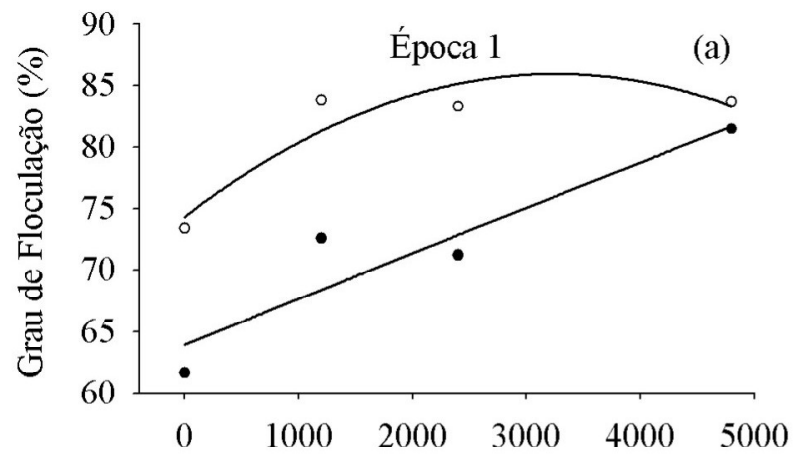

Dose de cama de frango $\left(\mathrm{kg} \mathrm{ha}^{-1}\right)$

- $\quad 0-20 \mathrm{~cm} \quad \mathrm{y}=0,0037 \mathrm{x}+63,96$ $\left(\mathrm{R}^{2}=0,87\right)$

- $\quad 20-40 \mathrm{~cm} \quad \mathrm{y}=-0,000001 \mathrm{x}^{2}+0,007 x+74,30$ $\left(\mathrm{R}^{2}=0,87\right)$

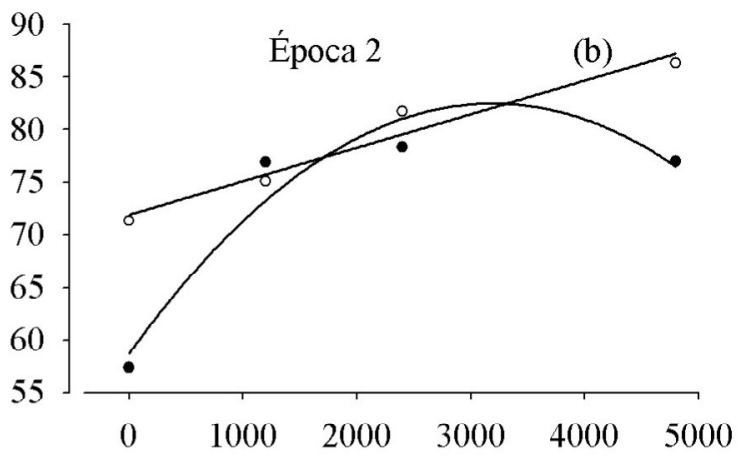

Dose de cama de frango $\left(\mathrm{kg} \mathrm{ha}^{-1}\right)$

- $\quad 0-20 \mathrm{~cm} \quad \mathrm{y}=0,000002 \mathrm{x}^{2}-0,015 \mathrm{x}+58,76$ $\left(\mathrm{R}^{2}=0,92\right)$

- $\quad 20-40 \mathrm{~cm} \quad \mathrm{y}=0,0032 x+71,90$

$\left(\mathrm{R}^{2}=0,95\right)$

Figura 2 - Valores médios do grau de floculação, para o Latossolo Vermelho Distrófico típico (LVd), em função dos tratamentos com cama de frango, nas profundidades de 0-20 e 20-40 cm, Épocas 1 (a) e 2 (b).

$\mathrm{Na}$ Época 1, para a profundidade de solo de 0-20 cm ocorre um incremento no GF com aumento das doses de cama aplicadas. Para a profundidade de $20-40 \mathrm{~cm}$, esse incremento ocorre até atingir um valor máximo de $86,55 \%$, com a aplicação de $3.500 \mathrm{~kg} \mathrm{ha}^{-1}$, a partir da qual há uma tendência de redução nos valores.

Para a Época 2, na profundidade de $0-20 \mathrm{~cm}$, há um aumento nos valores com aumento da dose de cama até o valor máximo de $86,88 \%$, com a dose de $3.750 \mathrm{~kg} \mathrm{ha}^{-1}$, tendendo a uma redução no GF a partir dessa dose. Na profundidade de $20-40 \mathrm{~cm}$, o GF aumenta linearmente com as doses de cama de frango aplicadas.

Os valores de GF obtidos são altos e semelhantes aos encontrados por D'Ándrea et al. (2002), em experimento em Latossolo Vermelho argiloso, sob uso de pastagem há 10 anos. O elevado grau de floculação no presente trabalho pode estar relacionado à adição de resíduo orgânico, que atuou indiretamente melhorando o ambiente para o desenvolvimento de plantas, aumentando a quantidade de raízes no perfil, resultando num efeito rizosférico elevado e benéfico para a agregação do solo (D'ANDRÉA et al., 2002).

A Figura $3 \mathrm{a}$ e $\mathrm{b}$ apresenta, respectivamente, os valores médios obtidos para a densidade do solo e porosidade total.

Analisando os valores de densidade do solo (Ds), somente houve efeito significativo das doses de cama de frango aplicadas para a época 1 , na profundidade de 20-40 $\mathrm{cm}(\mathrm{P}=0,02)$. Observa-se que os valores de Ds reduzem linearmente com aumento das doses de cama de frango aplicadas. Uma redução na densidade do solo também foi observada por Andreola et al. (2000), após 3 anos de adubação com cama de aves.

Para a porosidade total do solo $(\mathrm{Pt})$, somente houve efeito significativo das doses e profundidades de amostragem para a época 2. Para ambas as profundidades, ocorre uma redução nos valores da porosidade total, com aumento da dose de cama de frango aplicadas. $\mathrm{O}$ valor mínimo de porosidade $\left(29,97 \mathrm{~m}^{3} \mathrm{~m}^{-3}\right)$, na profundidade de 0-20 cm é obtido com aplicação de $3.500 \mathrm{~kg} \mathrm{ha}^{-1}$ de cama de frango. Na profundidade de $20-40 \mathrm{~cm}$, a menor porosidade $\left(30,13 \mathrm{~m}^{3} \mathrm{~m}^{-3}\right)$ é observada na dose de $3.750 \mathrm{~kg} \mathrm{ha}^{-1}$ de cama de frango; a partir desses valores, observa-se um incremento na porosidade total com o aumento das doses aplicadas. Nuernenberg et al. (1986) não observaram efeitos significativos na densidade do solo, estabilidade de agregados e porosidade total de uma Terra Roxa Estrutura adubada com camas de aves.

Na Tabelas 3 são apresentados os valores médios de ADA, GF, Ds e Pt para os tratamentos adicionais, nas épocas 1 e 2 . Observa-se que o comportamento dos tratamentos adicionais é semelhante ao dos tratamentos com cama de frango sem adição de adubo mineral. 


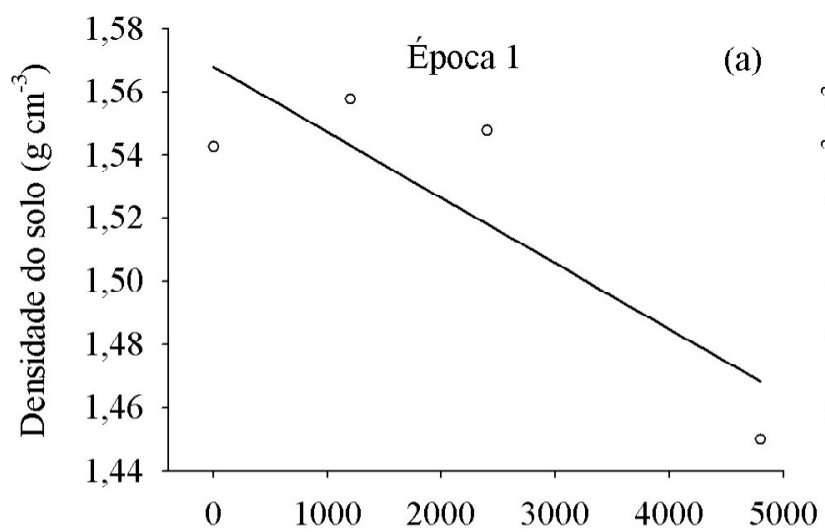

Dose de cama de frango $\left(\mathrm{kg} \mathrm{ha}^{-1}\right)$

- $\quad 20-40 \mathrm{~cm} \quad \mathrm{y}=-0,000021 \mathrm{x}+1,568$ $\left(\mathrm{R}^{2}=0,73\right)$

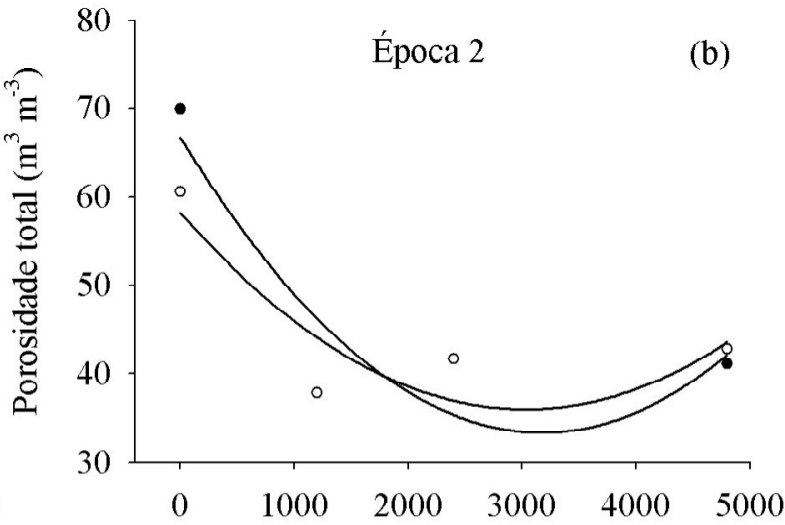

Dose de cama de frango $\left(\mathrm{kg} \mathrm{ha}^{-1}\right)$

- $\quad 0-20 \mathrm{~cm} y=0,000003 x^{2}-0,021+66,72$ $\left(\mathrm{R}^{2}=0,82\right)$

- $20-40 \mathrm{~cm} \quad \mathrm{y}=0,000002 \mathrm{x}^{2}-0,015 \mathrm{x}+58,25$ $\left(\mathrm{R}^{2}=0,78\right)$

Figura 3 - Valores médios de densidade do solo, para o Latossolo Vermelho Distrófico típico (LVd), em função dos tratamentos com cama de frango, na profundidade de $20-40 \mathrm{~cm}$ na época 1 (a) e da porosidade total, nas profundidades de 0-20 e 20-40 cm na época 2 (b).

Tabela 3 - Valores médios para os teores de argila dispersa em água, grau de floculação, densidade do solo e porosidade total em função dos tratamentos adicionais, nas épocas 1 e 2.

\begin{tabular}{lcccc}
\hline \multirow{2}{*}{ Tratamentos } & \multicolumn{5}{c}{ Época 1 } \\
\cline { 2 - 5 } * Adicional 1 & ADA & Grau de floculação & Densidade do solo & Porosidade total \\
\cline { 2 - 5 } ** Adicional 2 & $36,46 \mathrm{a}$ & $75,84 \mathrm{~b}$ & $1,52 \mathrm{a}$ & $40,15 \mathrm{a}$ \\
& $28,72 \mathrm{~b}$ & $84,81 \mathrm{a}$ & $1,47 \mathrm{a}$ & $40,55 \mathrm{a}$ \\
\cline { 2 - 5 } & \multicolumn{5}{c}{ Época 2 } \\
* Adicional 1 & $23,23 \mathrm{~b}$ & $78,63 \mathrm{~b}$ & $1,54 \mathrm{a}$ & $39,67 \mathrm{a}$ \\
** Adicional 2 & $29,48 \mathrm{a}$ & $84,05 \mathrm{a}$ & $1,52 \mathrm{a}$ & $39,96 \mathrm{a}$ \\
\hline
\end{tabular}

* $2400 \mathrm{~kg} \mathrm{ha}^{-1}$ de cama de frango + adubação mineral com $36 \mathrm{~kg} \mathrm{ha}^{-1} \mathrm{de} \mathrm{N}, 60 \mathrm{~kg} \mathrm{ha}^{-1} \mathrm{de} \mathrm{K}_{2} \mathrm{O}$ e $60 \mathrm{~kg} \mathrm{ha}^{-1}$ de $\mathrm{P}_{2} \mathrm{O}_{5}$ e profundidade de 0-20 cm; ** $2400 \mathrm{~kg} \mathrm{ha}^{-1}$ de cama de frango + adubação mineral com $36 \mathrm{~kg} \mathrm{ha}^{-1} \mathrm{de} \mathrm{N}, 60 \mathrm{~kg} \mathrm{ha}^{-1} \mathrm{de} \mathrm{K}_{2} \mathrm{O}$ e $60 \mathrm{~kg} \mathrm{ha}^{2} \mathrm{de}_{2} \mathrm{O}_{5}$ e profundidade de 20-40 cm. Médias seguidas de mesma letra minúscula, na coluna, não diferem entre si pelo teste t, com nível nominal de significância de 5\%.

Para a Época 1, os valores de ADA são maiores para a profundidade de $0-20 \mathrm{~cm}$ (adicional 1), conseqüentemente, nessa profundidade, ocorre o menor grau de floculação das argilas. Para a densidade do solo e porosidade total, não houve diferença significativa entre os tratamentos $(\mathrm{P}>0,05)$.

$\mathrm{Na}$ Época 2, os menores valores de ADA ocorrem para a profundidade de $0-20 \mathrm{~cm}$. Os menores teores, nessa profundidade, devem estar relacionados ao desenvolvimento da braquiária ao longo do tempo, o qual pode ter promovido maior agregação das partículas do solo. Embora o GF seja maior para a profundidade de 20-40 $\mathrm{cm}$, observa-se uma tendência à redução desse, com o tempo, na camada superficial do solo. Não foi observada diferença significativa entre os tratamentos para densidade do solo e porosidade total.

Em ambas as profundidades de solo, ocorreu uma redução nos teores de ADA e aumento no grau de floculação do solo, à medida que aumentaram-se as doses de cama de frango aplicadas, sendo esses efeitos mais expressivos na segunda época de amostragem. 
As doses de cama de frango aplicadas promoveram uma pequena redução nos valores de densidade do solo e elevação da porosidade total, independentemente da profundidade e épocas de amostragem.

Os atributos físicos do solo avaliados responderam com maior intensidade para doses de cama de frango, variando de 2.666 a $3.750 \mathrm{~kg} \mathrm{ha}^{-1}$.

\section{REFERÊNCIAS BIBLIOGRÁFICAS}

ANDREOLA, F. Propriedades físicas e químicas do solo e produção de feijão e de milho em uma Terra Roxa Estruturada em resposta a cobertura vegetal de inverno e a adubação orgânica e mineral. 1996. 103 f. Tese (Doutorado em Agronomia) - Universidade Federal de Viçosa, Viçosa, 1996.

ANDREOLA, F.; COSTA, L. M.; OLSZEVSKI, N. Influência da cobertura de inverno e da adubação orgânica e, ou mineral sobre as propriedades físicas de uma Terra Roxa Estruturada. Revista Brasileira de Ciência do Solo, Campinas, v. 24, n. 4, p. 587-865, out./ dez. 2000.

BERTOL, I.; ALMEIDA, J. A.; ALMEIDA, E. X.; KURTZ, C. Propriedades físicas do solo relacionadas a diferentes níveis de oferta de forragem de capim-elefante-anão cv. Mott. Pesquisa Agropecuária Brasileira, Brasília, v. 35, n. 5, p. 1047-1054, maio 2000.

BLAKE, G. R.; HARTGE, K. H. Bulk density. In: KLUTE, A. (Ed.). Methods of soil analysis: physical and mineralogical methods. 2. ed. Madison: American Society of Agronomy, 1986. p. 363-375.

CAMPOS, B. C.; REINERT, D. J.; NICOLOD, R.; CASSOL, L. C. Dinâmica da agregação induzida pelo uso de plantas de inverno para cobertura do solo. Revista Brasileira de Ciência do Solo, v. 23, n. 2, p. 386-391, abr./ jun. 1999.

D’ANDRÉA, A. F.; SILVA, M. L. M.; CURI, N.; FERREIRA, M. M. Atributos de agregação indicadores da qualidade do solo em sistemas de manejo na região dos cerrados no sul do estado de Goiás. Revista Brasileira de Ciência do Solo, Viçosa, v. 26, p. 10471054, out./dez. 2002.

DAY, P. R. Particle fractionation and particle-size analysis. In: BLACK, C. A. (Ed.). Methods of soil analysis: physical and mineralogical properties including statistics of measurement and sampling: part 1. Madison: American Society of Agronomy, 1965. p. 545-567.

EDWARD, J. O Brasil que planta e colhe dinheiro. Veja, São Paulo, v. 37, n. 30, p. 14-21, abr. 2004.

\section{EMPRESA BRASILEIRA DE PESQUISA}

AGROPECUÁRIA. Centro Nacional de Pesquisa de Solos. Manual de métodos de análise de solo. 2. ed. rev. e atual. Rio de Janeiro, 1997. 212 p.

\section{EMPRESA BRASILEIRA DE PESQUISA}

AGROPECUÁRIA. Centro Nacional de Pesquisa de Solos. Sistema brasileiro de classificação de solos. 2 . ed. Rio de Janeiro, 2006. 306 p.

ERNANI, P. R. Utilização de materiais orgânicos e adubos minerais na fertilização do solo. 1981. $82 \mathrm{f}$. Dissertação (Mestrado em Agronomia) - Universidade Federal do Rio Grande do Sul, Porto Alegre, 1981.

FERREIRA, D. F. Análise estatística por meio do SISVAR para Windows versão 4.0. In: REUNIÃO BRASILEIRA DA SOCIEDADE INTERNACIONAL DE BIOMETRIA, 45., 2000, São Carlos. Programas e Resumos... São Carlos: UFSCar, 2000. p. 235.

GIANELLO, C.; ERNANI, P. R. Rendimento de matéria seca de milho e alterações na composição química do solo pela incorporação de quantidades crescentes de cama de frangos, em casa de vegetação. Revista Brasileira de Ciência do Solo, Viçosa, v. 7, n. 3, p. 285 290, set./dez. 1983.

HOLANDA, J. S. de; MIELNICZUK, J.; STAMMEL, J. G. Utilização de esterco e adubo mineral em quatro sequiências de culturas em solo de encosta basáltica do Rio Grande do Sul. Revista Brasileira de Ciência do Solo, Campinas, v. 6, n. 1, p. 47-51, jan./abr. 1982.

KIEHL, E. J. Manual de edafologia: relações solo-planta. São Paulo: Ceres, 1979. 262 p.

MELLO, S. C.; VITTI, G. C. Desenvolvimento do tomateiro e modificações nas propriedades químicas do solo em função da aplicação de resíduos orgânicos, sob cultivo protegido. Horticultura Brasileira, Brasília, v. 20, n. 2, p. 200-206, jun. 2002. 
MENEZES, J. F. S.; ALVARENGA, R. C.; SILVA, G. P.; KONZEN, E. A.; PIMENTA, F. F. Cama de frango na agricultura: perspectivas e viabilidade técnica econômica. Rio Verde: FESURV, 2004. (Boletim técnico, 3).

NUERBERG, N. J.; STAMMEL, J. G.; CAMANUREA, M. S. V. Efeito de sucessão de culturas e tipos de adubação em características físicas de um solo da encosta basáltica Sul-Rio-Grandense. Revista Brasileira de Ciência do Solo, Campinas, v. 10, n. 3, p. 185-190, set./ dez. 1986.
PALADINI, F. L. S.; MIELNICZUK, J. Distribuição de tamanho de agregados de solo Podzólico VermelhoEscuro afetado por sistemas de culturas. Revista Brasileira de Ciência do Solo, Viçosa, v. 15, n. 2, p. 135140, maio/ago. 1991.

SARRUDE, J. R.; HAAG, H. P. Análises químicas em plantas. Piracicaba: ESALQ, 1974. 56 p.

SILVA, I. F.; MIELNICZUK, J. Ação do sistema radicular de plantas na formação e estabilização de agregados do solo. Revista Brasileira de Ciência do Solo, Campinas, v. 21, n. 1, p. 113-117, jan./mar. 1997. 